\title{
Thales SESO silver coatings for space programs
}

Patrick Robert, Christian Du Jeu, Cédric Cammarata, Mailys Thorigny, Karine Mathieu, et al.

Patrick Robert, Christian Du Jeu, Cédric Cammarata, Mailys Thorigny, Karine Mathieu, Mattieu Tatat, Vincent Costes, Fabrice Champandard, Aurélien Suau, Guillaume Briche, Jean-François Blanc, "Thales SESO silver coatings for space programs," Proc. SPIE 11852, International Conference on Space Optics - ICSO 2020, 118524M (11 June 2021); doi: 10.1117/12.2599795

SPIE Event: International Conference on Space Optics - ICSO 2021, 2021, Online Only 


\section{International Conference on Space Optics-ICSO 2020}

Virtual Conference

30 March-2 April 2021

Edited by Bruno Cugny, Zoran Sodnik, and Nikos Karafolas
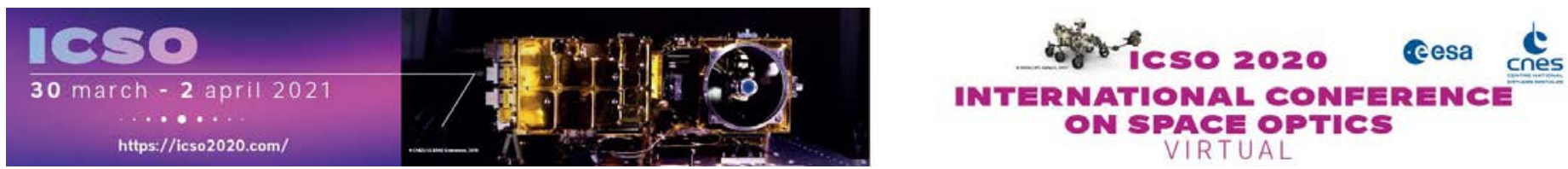

\section{Thales SESO silver coatings for space programs}

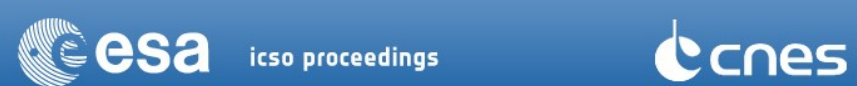

International Conference on Space Optics - ICSO 2020, edited by Bruno Cugny, Zoran Sodnik,

Nikos Karafolas, Proc. of SPIE Vol. 11852, 118524M · (c) 2021 ESA and CNES

CCC code: $0277-786 X / 21 / \$ 21 \cdot$ doi: $10.1117 / 12.2599795$ 


\author{
Thales SESO Silver coatings for Space programs \\ Patrick Robert ${ }^{1}$, Christian Du Jeu $^{1}$, Cédric Cammarata ${ }^{1}$, Mailys Thorigny ${ }^{1}$ \\ Karine Mathieu ${ }^{2}$, Matthieu Tatat ${ }^{2}$, Vincent Costes ${ }^{2}$ \\ Fabrice Champandard ${ }^{3}$, Aurélien Suau ${ }^{3}$, Guillaume Briche ${ }^{3}$, Jean-François Blanc ${ }^{3}$ \\ ${ }^{1}$ Thales-SESO, 530 rue Frédéric Joliot 13290 Aix-les-Milles, France \\ patrick.robert / christian.dujeu/ cedric.cammarata/ mailys.thorigny @ fr.thalesgroup.com \\ ${ }^{2}$ CNES, 18 avenue Edouard Belin, 31400 Toulouse, France \\ ${ }^{3}$ Thales Alenia Space, 5 Allée des Gabians, 06150 Cannes, France
}

\begin{abstract}
Silver protected is one of the most required coating for space observation telescopes covering the wavelength range from $430 \mathrm{~nm}$ to infra-red. Many challenges have to be addressed in such coatings including high efficiency over the wide spectrum, high durability with behavior in AIT conditions and during flight. Thales SESO has already produced more than 166 total space mirrors from which 87 are flying successfully since many years. Most of them are coated with protected silver coatings.

For over the past 20 years, Thales SESO has enhanced the characteristics of our coating related to its durability in acceptance test conditions, its mechanical stability when going to vacuum and its behavior toward space aggressions such as ATOX or radiations. A lot of the corresponding developments were substantially sustained by CNES, together with Thales Alenia Space through different French programs.

Previous realizations include Pléiades, French national program, MTG mirrors both for sounders (IRS instrument) and imagers (FCI instrument), Sentinel 3 with $\mathrm{Na}$ and $\mathrm{Ob}$ mirrors and different other export programs. The last improvements were made in the frame of TANGO program for Thales Alenia Space/CNES, with improved adhesion during acceptance tests, with ability to apply the full coating process on sub-assemblies including glued parts, and with reduction in the stress induced on the substrate. The performance and uniformity were demonstrated on $1700 \mathrm{~mm}$ diameter in Thales SESO STEP large coating chamber.

Through these different developments Thales SESO has gained maturity in the contribution of the coating on stress induced in the mirror as well as its stability when going to vacuum. We now perfectly anticipate this effect in the polishing process.

Here after, you find an overview of the Thales SESO realizations starting from Pléiades first results to the status achieved with the last improvements on TANGO program and future prospective developments.
\end{abstract}

Keywords: Mirror, reflective coating, protected silver, space

\title{
1. INTRODUCTION
}

Most of space optical experiments include mirrors. Those mirrors which can reach size above $1 \mathrm{~m}$ have to be coated to reflect as much light as possible regarding the spectrum of interest. Apart from very specific mirrors, generally of small size, which address a very limited range, the standard reflective coatings are based on metallic layers. Depending on the range of interest, preferred solution is either Aluminum (addressing mainly UV range thanks to its large bandwidth down to even less than $100 \mathrm{~nm}$ ), Gold (mainly for infrared range, as far as it is efficient starting from $700 \mathrm{~nm}$ ) or Silver (able to cover ranges from about $400 \mathrm{~nm}$ to large IR).

Drawback of aluminum is its limited efficiency (about $90 \%$ maximum up to $1 \mu \mathrm{m}$ ). For a telescope including up to 5 reflective surfaces the global efficiency is then $59 \%$ maximum and even $44 \%$ in the range close to $850 \mathrm{~nm}$ leading to a major loss in performance. Reversely Aluminum, in the protected version, is interesting due to its high stability in most of environmental conditions. Therefore this solution is generally limited to UV demanding missions (e.g. LUVOIR), for which other solutions are not adequate.

Gold protected coating is also known as being very stable chemically, which allows to address ranges above $700 \mathrm{~nm}$ in quite a comfortable way. At Thales SESO this solution has been privileged for missions such as MIPAS, IASI and even 
some mirrors of MTG (in the IRS instrument). It is also used for its thermo-optical properties with a very low emissivity (less than 0.02 when applied on specular surfaces). It has therefore also been chosen by Thales SESO on elements such as cryostat (French National Program), some sunshields (IASI) and thermal control on the main barrels for MTG Cold optics. In these applications it has been qualified down to liquid nitrogen temperature and up to $120^{\circ} \mathrm{C}$ ( $80 \mathrm{~K}$ to $393 \mathrm{~K}$ ) over 120 cycles. With its protection it remains easily cleanable which is comfortable for AIT activities after coating deposition.

For some applications gold is even used unprotected to still gain on performance (once again thanks to its high chemical stability). This is the case at Thales SESO for the cube corners of MTG IRS instrument. Then cleanability is more limited and some care has to be taken not to damage the coated surface.

But whenever the range of interest addresses visible range and a high efficiency is requested the best candidate remains the silver based coating. Depending on the exact design and material chosen for the protective layer, the average reflectance is about $98 \%$ from $450 \mathrm{~nm}$ to above $14 \mu \mathrm{m}$. The only generally stated concern with silver based coatings are addressing its stability to the different types of environments it has to survive :

- Ground conditions during AIT activities including temperature and humidity

- Effect of space environment including vacuum, radiations, UV exposure and ATOX exposure.

Silver is much more sensitive to chemical aggressions than aluminum or gold. Even when protected it might degrade when exposed to such environments as mentioned in many literatures [1,2].

Despite this drawback Thales SESO has applied this type of coating for most of the space programs we had to run for observation instruments, as far as their need covers the visible range.

This paper presents our achievements on this coating including the last developments supported by Thales Alenia Space and the CNES. The corresponding level of maturity has satisfactorily been applied on TANGO dia. $1.5 \mathrm{~m}$ demonstrator mirror.

\section{SILVER PROTECTED COATING: DESIGNS AND MATERIALS}

Many different version of the so called protected silver coating are available among the different manufacturers. Parameters include the nature of the protective coating (generally based on oxides), its thickness, the nature of the adhesion system (single or multi-layer, material selection), possible passivation barrier between the silver layer and the protective coating as detailed in the Gemini design [3].

The deposition parameters are also part of the stability and resistance of produced coating. This includes deposition speed, partial pressure adjustment, substrate temperature, deposition technology.

Last, the cleanliness of the substrate prior to the coating is also a driver. A chemically clean surface is the guarantee of a low risk of evolution of the coating throughout its whole life.

The main considerations in the adjustment of these parameters are the following:

- First the efficiency : as mentioned above, the great expectation from a protected silver coating is its high reflectance. Still the thickness and nature of the protective layer impacts the exact efficiency, mainly for short wavelength range when speaking of visible range [1]. The following graph shows different adjustment on this protective layer depending on the parameters adjustment : 


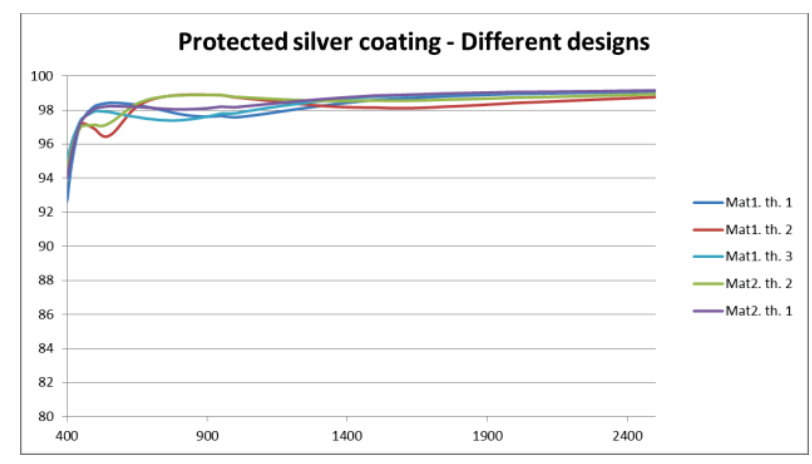

Note :

Figure 2-1 - Impact of coating design on theoretical reflectance

In parallel Thales SESO also worked on ground applications with enhanced silver coating getting increased performance down to $380 \mathrm{~nm}$.

Such coating has been qualified for the ground application :

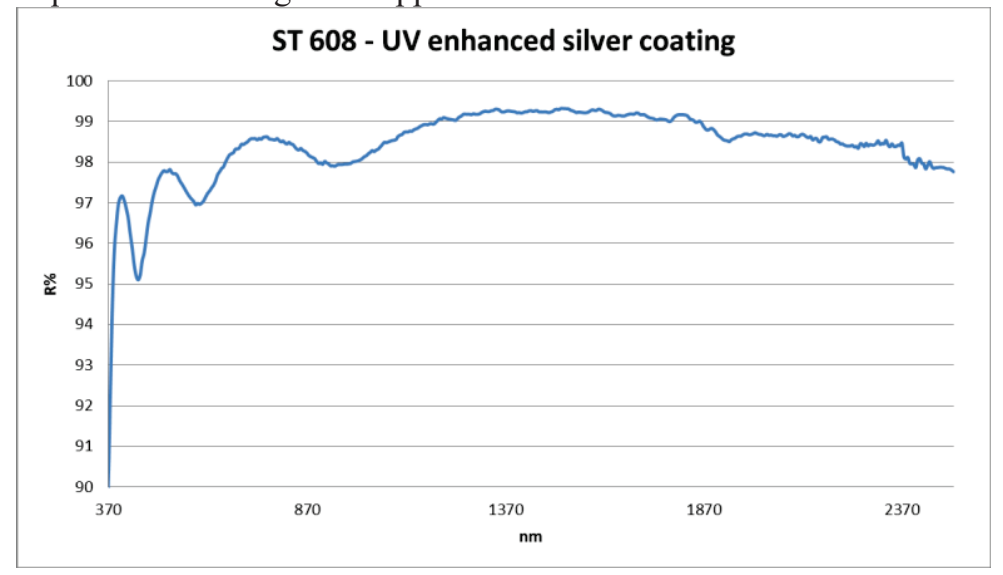

Figure 2-2 - Ground qualified enhanced UV silver coating

- The second consideration is the resistance to environment both for ground activities and for flight conditions. Ground life includes AIT activities (both at the supplier and at the customer), testing sequences, transportation and storage. More and more, related to the different models to be manufactured and assembled for one instrument, ground lifetime increases to about a decade. Therefore the environmental tests, as generally covered by MIL or ISO standards are considered in the qualification of such coating. Last the ECSS included recently an update of the test conditions for optical coatings in ECSS-Q-ST-70-17C (February 2018).

For space need, the considerations concentrate on resistance to radiations (including UV exposure), resistance to ATOX and stability of the performance (reflectance and WFE of the coated mirror) when changing from ambient to vacuum.

- The last consideration is generally the impact of the coating on the WFE of the mirror due to the stressed generated by this coating. From the "as polished" status, the coating induces a modification of the WFE due to some stress (intrinsic or extrinsic) as found in many literature sources [4]. The first order is a change in curvature, but for most of the very lightweighted mirrors such as the one used in space instruments, some quilting or higher order deformation is also generated. Dealing with this effect requires to have a good prediction of the induced effect which is then anticipated in the final polishing steps (e.g. a concave effect is anticipated by polishing the mirror convex in the opposite amplitude). Then some finite element modeling allows to anticipate correctly the effect to reach a nominally perfect mirror after coating. Then another issue is the possible evolution of the stress related to the change to vacuum : some stress distribution can occur depending on the exact quality of the protective layer. This parameter has to be evaluated through the 
qualification of the coating to avoid a drift of the performance during flight, only linked to the change in stress distribution.

\section{MORE THAN 20 YEARS OF PROTECTED SILVER COATING AT THALES SESO}

Thales SESO has been developing its own optical coating means and processes since mid of the eighties.

We operate mainly evaporation coaters but also some magnetron sputtering equipment.

The coatings we deposit were first optimized and qualified on the small machines we had at the beginning and progressively transferred on the new one.

Apart from standard coaters from usual manufacturers, Thales SESO has also developed a large coating chamber capable of the coating of $1.7 \mathrm{~m}$ large optics, with a high uniformity (see below the results achieved on this machine).

AT Thales SESO the machine is called STEP.

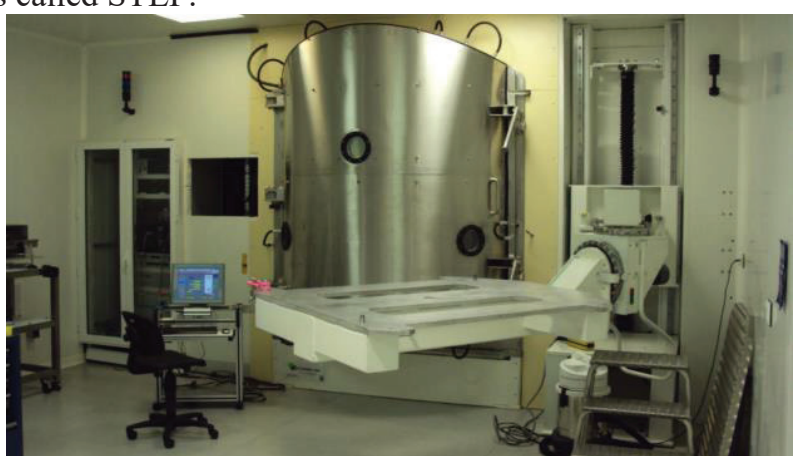

Figure 3-1 - Thales SESO STEP coating machine, $1.7 \mathrm{~m}$ capable

This machine includes the following features:

- $\quad$ Load up to $500 \mathrm{~kg}$

- Fully automated recipes

- 2 e-beams, 2 thermal evaporators

- Quartz control monitoring

- Process temperature up to $250^{\circ} \mathrm{C}$

- $\quad$ Cryogenic pumps

- $\quad$ Loading arm for safe handling

- $\quad$ Clean room ISO 7

It is operational since 2010 and we have qualified most of our coatings for space applications (and others) on this machine.

Beside these coating means, we also extensively worked on the preparation of the substrate, which specifically on silver coating, is a driver to good ageing of the produced coating.

We therefore have developed a specific chemical preparation before coating allowing to remove all residual contaminants from the mirror surface. This procedure uses specific cleaning means able to address the large size mirror mentioned here after.

As underlined above our handling means also include all necessary crane/handling arm to handle and load the very expensive optical parts we coat with full security.

We first list here below some of our realizations over the years, to come to the last enhancements made in the frame of some development supported by Thales Alenia Space and CNES to still improve all the already known features of our protected silver coatings, some of them flying for more than 20 years.

\subsection{Brief history of the space mirrors coatings developed at Thales SESO}

Over the first decade of the coating history at Thales SESO the produced coatings addressed mainly ground applications (astronomy, flight simulation, military applications, scientific research with synchrotrons, ...). We yet progressed to 
deliver standard coatings including V or BBAR coatings, mirrors (metallic, protected metallic, full dielectric or enhanced metallic coatings), dichroic filters and reflective or AR coatings for laser applications.

Those elements were produced on typically $\varnothing 700 \mathrm{~mm}$ box coaters and qualified to requested standards (typically MIL, DIN or NF standards at the beginning and progressively ISO and ECSS standards.

Our first great experience in the field of space programs came with MIPAS program mid of the nineties. This program under ESA control allowed us to produce protected gold coatings applied on the different MIPAS mirrors. MIPAS remained operational between 2002 and 2012.

We then coated some lightweighted zerodur mirrors in the diameter range $650 \mathrm{~mm}$ for the ETGAR mission.

Our protected gold coating was also applied on mirrors for RVS and on IASI HOP mirrors and IASI sunshield which space lifetime is 15 years. The mirrors were coated beginning of 2000s, for a launch of the first satellite in 2006.

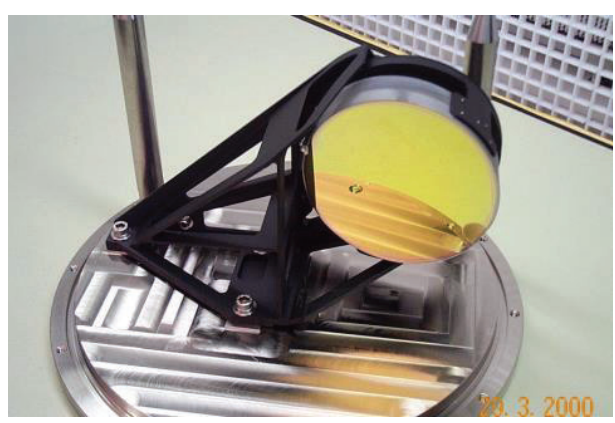

Figure 3-2 - IASI HOP gold coated mirror

Thales SESO protected gold coating on titanium was qualified with 120 cycles from liquid nitrogen and up to $120^{\circ} \mathrm{C}(80$ $\mathrm{K}$ to $393 \mathrm{~K}$ ) for low emissivity need.

But the great step we had in the field of protected silver coating really started with the Pléiades satellite generation and similar export missions. We then demonstrated a stability versus radiation above $70 \mathrm{Mrad}$ cumulated dose.

Pléiades first mirrors were coated in 2004 and the mission is still operational more than 15 years later.

(a)

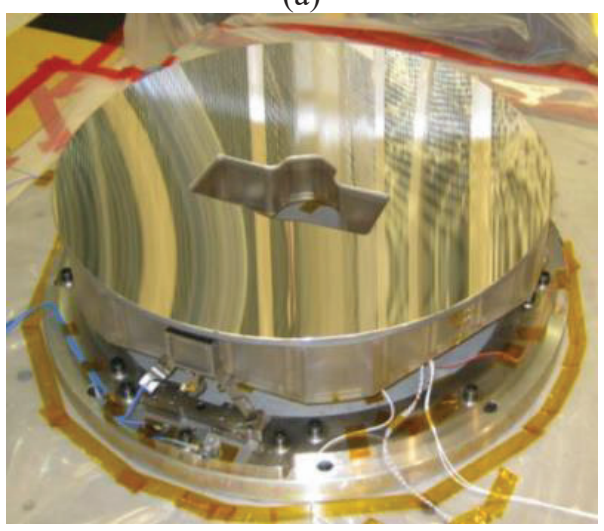

(b)

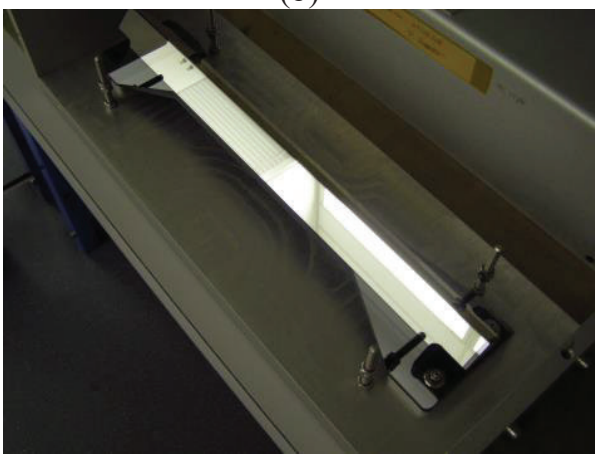

Figure 3-3 - Some of Thales SESO realizations for space silver coated mirrors

(a) Pléiades M1 mirror during tests - (b) Pléiades center SiC mirror

From this phase we improved our protected silver coating in different steps. 
The first major step was to improve the stability when going to vacuum : on initial realizations there was a slight drift of the curvature due to the deposition conditions of the protective layer. Even though very limited and not impacting the missions already launched, this effect had to be cancelled.

We succeeded in demonstrating this enhancement in a qualification in 2010. Our protected silver coatings are now fully stable when going to vacuum as demonstrated by the following curve produced on a sample presenting a high sensibility to this effect (sample very thin regarding its diameter).

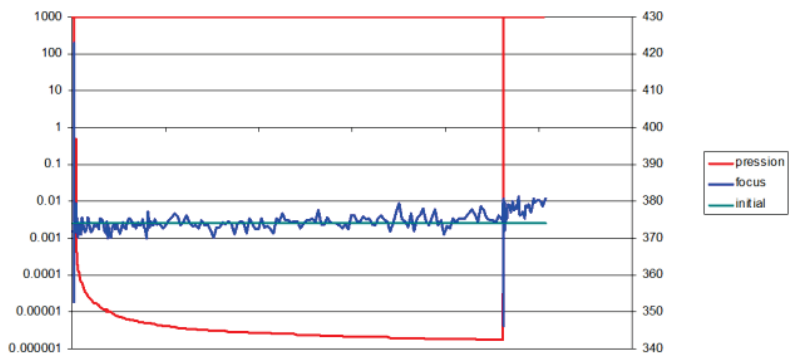

Figure 3-4 - Stability of Thales SESO silver coated sample when going to vacuum over 2 weeks (focus in nm PTV)

The stability was also verified further to thermal/humidity cycles and then through more than 3 years storage at ambient without any evolution.

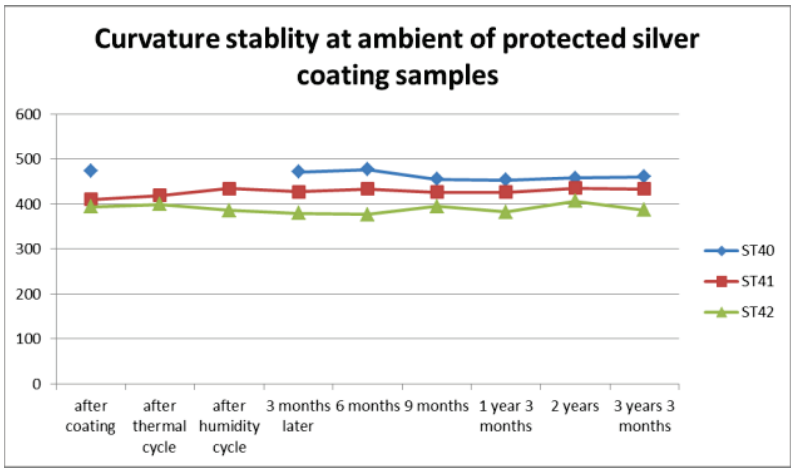

Figure 3-5 - Stability of Thales SESO silver coated samples over time (focus in nm PTV)

This additional step was reached at the time of the qualification on our large STEP coating machine (capable of the coating of mirrors up to $1.7 \mathrm{~m}$ diameter).

This coating was also demonstrated to sustain $2.410^{21} \mathrm{at} / \mathrm{cm}^{2}$ ATOX (Atomic Oxygen) exposure without detectable degradation on the reflectance.

This version of the coating was used for the coating of many different programs including

- $\quad$ French National program telescope (with 3 models). The corresponding telescopes are now operational in space for the two first models.

- $\quad$ Export program with large primary mirror over $1 \mathrm{~m}$ diameter also starting to operate in space

- MTG Telescope Optics mirrors for which Thales SESO additionally demonstrated the capability of our protected silver coating to sustain up to 99 solar constants exposure without degradation. 


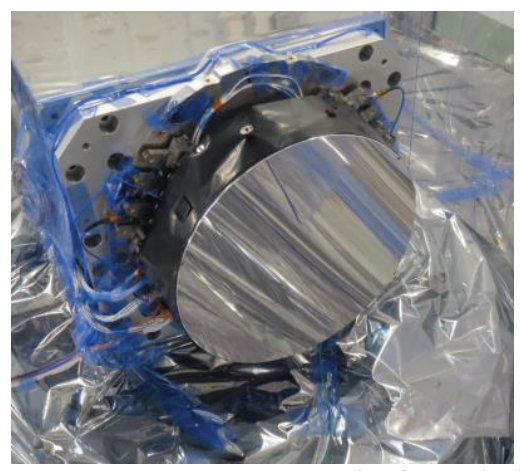

Figure 3-6 - MTG M1FCI coated mirror during tests

\subsection{Last improvements}

In the frame of some additional developments with participation of Thales Alenia Space and CNES, Thales SESO still improved its silver coating performances.

The ameliorations were covering three axis :

- Enhanced adhesion : though there is nominally no adhesion need on the coated mirrors, one of the standard test to good health of the coating relies on a tape adhesion test as mentioned in the different standards for optical coatings (MIL, ISO or ECSS). Some work has been done to guarantee an enhanced adhesion from previous status by working on the part of the design underneath the silver layer. The results are fully satisfactory and were demonstrated with different runs on large mirrors $(0.8 \times 0.3 \mathrm{~m})$ with up to 40 tests on each mirror.

- Reduced stress : the stress induced by the coating needs, as detailed above, to be managed through polishing anticipation. The process still leaves some residue due to discrepancy between prediction and achieved performance. By reducing the deformation induced by the coating the corresponding residue is also minimized. We managed with the new design to reduce by $30 \%$ the deformation induced by our coating. This was demonstrated both at sample level and on preliminary mockup.

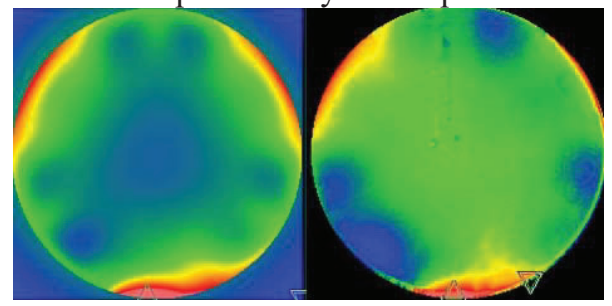

Figure 3-7 - Comparison of the simulation and the measured WFE on a $680 \mathrm{~mm}$ diameter mockup

- Capability of coating bonded mirrors assemblies: this action is linked to the temperature limitations of the subassemblies we have to address. The coating of bonded assemblies is a driver toward the maximum temperature to be reached during the coating. By applying a plasma cleaning process on the mirror just before the coating inside the vacuum chamber, we demonstrated the good behavior as mentioned above to the adhesion test and are now able to coat a mirror with bonded elements. Such bonded elements can cover glass to glass bonding as well as mechanical parts to glass bonding.

It is to be noted that the updated coating has been qualified through this development with at least similar qualification level as the previous version to all relevant adhesion, thermal and humidity test.

Through this development Thales SESO also worked on the improvement of the uniformity of the complete diameter of the chamber (meaning up to the $1.7 \mathrm{~m}$ diameter coating capability).

The reached uniformity is the following (without uniformity masking) : 


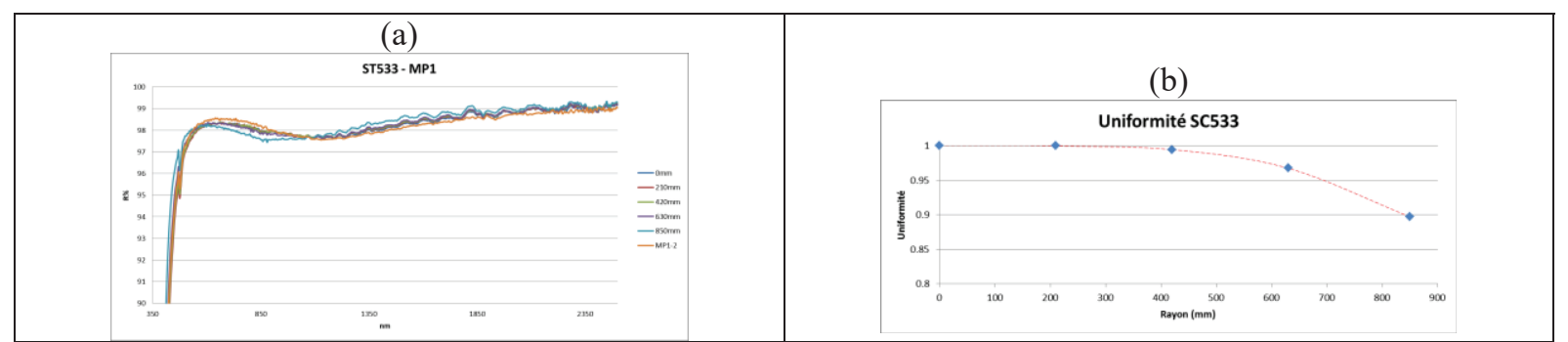

Figure 3-8 - Uniformity effect on STEP machine

(a) Reflectance curves from center to the edge of the coated area - (b) corresponding thickness uniformity

We can observe that the thickness uniformity we can guarantee is less than $1 \%$ over $900 \mathrm{~mm}$ diameter, less than $5 \%$ up to $1400 \mathrm{~mm}$ diameter and $10 \%$ up to the full capacity of the machine. To our knowledge this one of the best performance over this type of large machine.

By the way the impact on the reflectance is less than $0.5 \%$ over the full diameter of the machine.

We also verified that this improvement didn't modify the WFE stability when going to vacuum over a 10 days test :

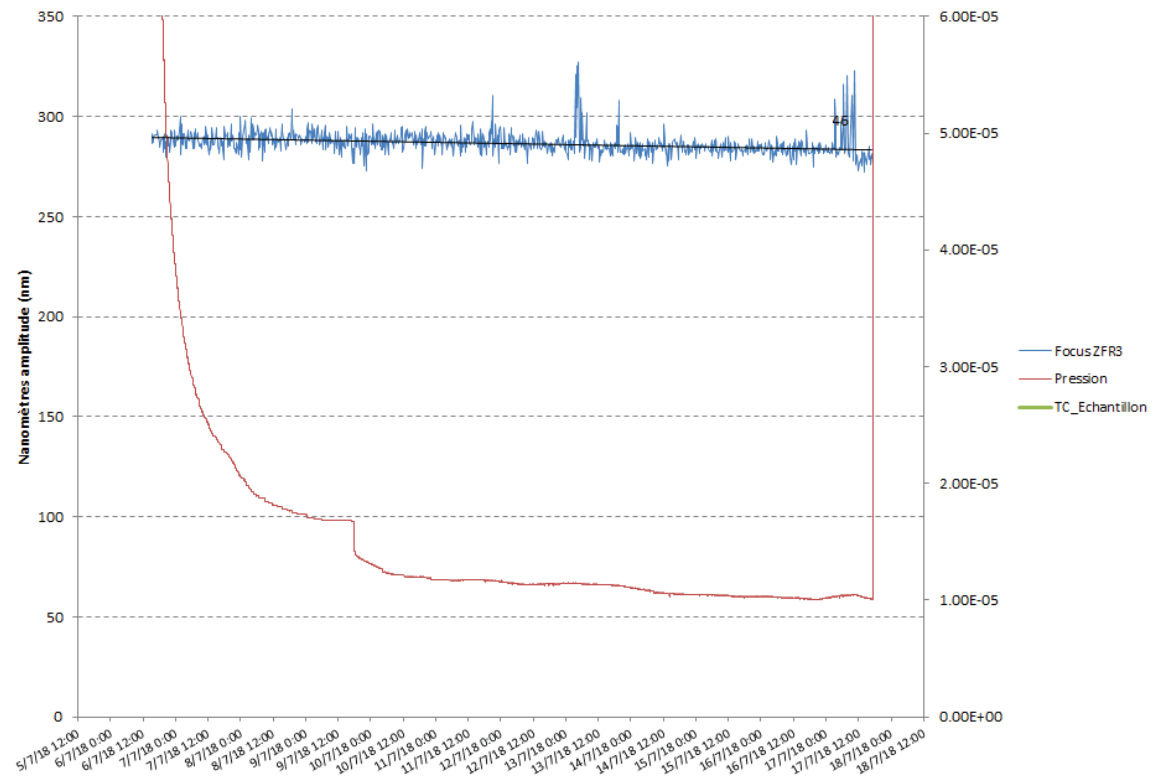

Figure 3-9 - Stability of Thales SESO new silver coated sample when going to vacuum over 10 days (focus in nm PTV)

These improvements were used for the coating applied on TANGO M1 lightweighted mirror. This is a very lightweighted zerodur mirror, $1.5 \mathrm{~m}$ diameter reaching a level of $25 \mathrm{~kg} / \mathrm{m}^{2}$. It is therefore very sensitive to all the parameters induced by the coating.

This mirror was coated with full satisfaction and confirmed the predicted performances. 


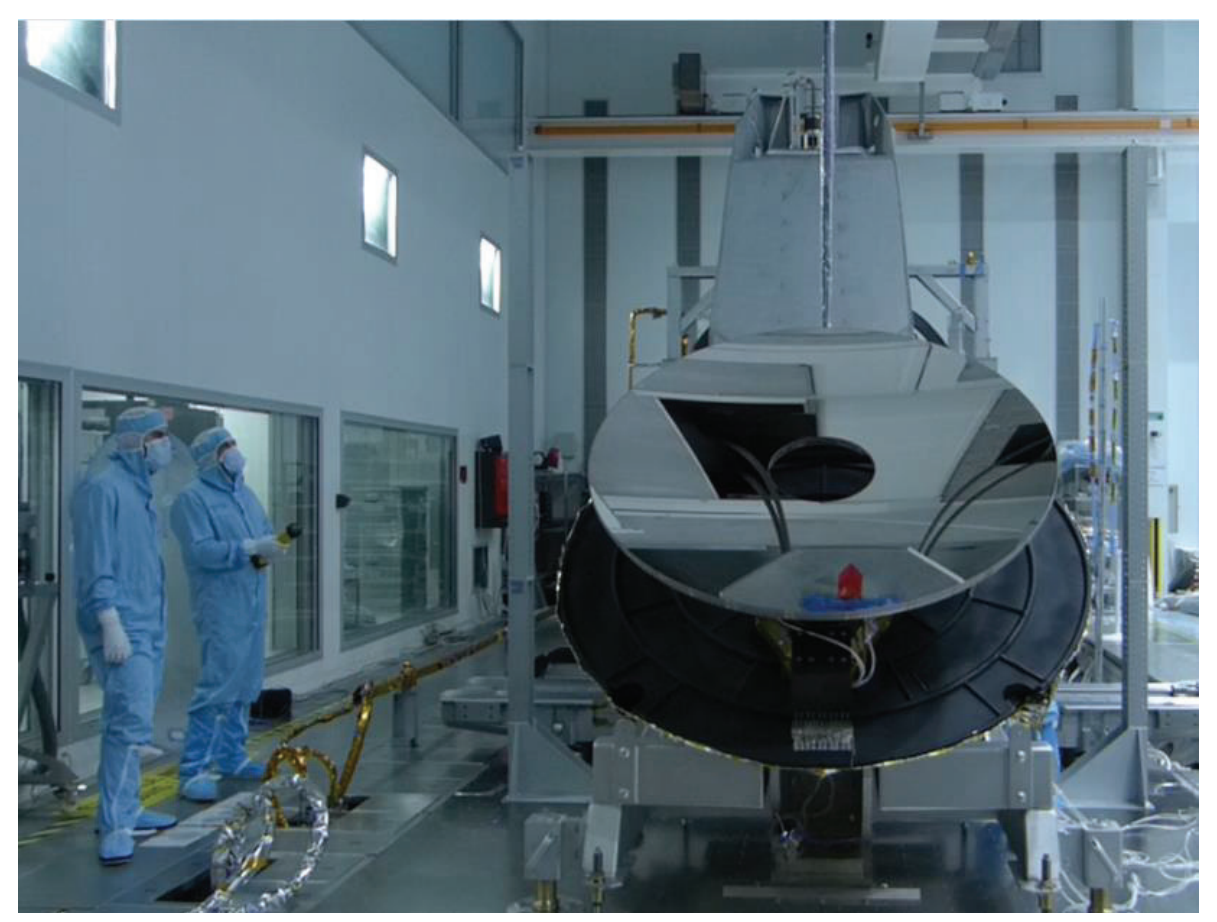

Figure 3-10 - TANGO zerodur M1 mirror in testing sequence at Thales Alenia Space Cannes

\section{CONCLUSION}

Thales SESO has developed protected silver coatings for space applications some of which are flying for more than 15 years.

Thanks to CNES and Thales Alenia Space support Thales SESO still has improved the performances of this type of coating

- Highest durability (mainly adhesion improvement)

- Lower impact on WFE, inducing lower prediction residual error

- $\quad$ Compatibility with glued assemblies (glass to glass and mechanics to glass)

The corresponding reflectance addresses the wavelength ranges from $400 \mathrm{~nm}$ to more than $14 \mu \mathrm{m}$, with reflectance above $96 \%$ absolute (98\% average) from $450 \mathrm{~nm}$ up.

Such coatings can be applied on many different substrates (including Zerodur, fused silica, SiC, Nickel plated Beryllium or aluminum, ...) and for size up to $1700 \mathrm{~mm}$ diameter with minimum uniformity variation $(<0.5 \%$ on reflectance).

\section{AKNOWLEDGEMENTS}

\section{MIPAS Program}

European Space Agency (ESA)

Pléiades Program, French National program, TANGO program

Centre National d'Etudes Spatiales (CNES)

\section{MTG Program}

The work for the Meteosat Third Generation (MTG) Programme has been performed under contract from the European Space Agency (ESA) with OHB and Thales Alenia Space. 


\section{REFERENCES}

[1] Denis Garoli, Luis V. Rodriguez De Marcos, Juan I. Larruquert, Alain J. Corso, Remo Proietti Zaccaria and Maria G. Pelizzo - Mirrors for Space Telescopes: Degradation Issues - Appl. Sci. 2020, 10, 7538

[2] Kelsey A. Folgner, Chung-Tse Chu, Scott D. Sitzman, Sean C. Stuart, and James D. Barrie - Investigations of corrosion feature development on protected silver mirrors during accelerated environmental exposure

[3] Maxime Boccas, Tomislav Vucina, Claudio Araya, Esteban Vera, Clayton Ahhee, "Coating the 8-m Gemini telescopes with protected silver," Proc. SPIE 5494

[4] Krishna Seshan - Handbook of thin-film deposition processes and techniques - 0-8155-1442-5 